\title{
Dimensions of responsibility in medical genetics: exploring the complexity of the "duty to recontact"
}

\author{
Shane Doheny $\mathbb{1}^{\mathrm{a} *}$, Angus Clarke $\oplus^{\mathrm{a}}$, Daniele Carrieri ${ }^{\mathrm{b}}{ }^{\mathrm{b}}$, \\ Sandi Dheensa ${ }^{\mathrm{c}}$, Naomi Hawkins ${ }^{\mathrm{d}} \mathrm{d}$, Anneke Lucassen ${ }^{\mathrm{e}}{ }^{\mathrm{e}}$, \\ Peter Turnpenny ${ }^{\mathrm{f}}$ and Susan Kelly (i) ${ }^{\mathrm{g}}$
}

${ }^{a}$ Division of Cancer and Genetics, Cardiff University School of Medicine, Cardiff, UK;

${ }^{b}$ Exeter Medical School, Exeter, UK; ${ }^{c}$ School of Social and Community Medicine, Bristol, UK; ${ }^{d}$ School of Law, University of Exeter, Exeter, UK; ${ }^{e}$ Faculty of Medicine, University of Southampton, UK, ${ }^{f}$ Peninsula Clinical Genetics Service, Royal Devon \& Exeter Hospital, Exeter, UK; ${ }^{g}$ Department of Sociology and Philosophy, University of Exeter, Exeter, UK

(Received 22 January 2018; final version received 7 August 2018)

\begin{abstract}
Discussion of a "duty to recontact" emerged as technological advances left professionals considering getting back in touch with patients they had seen in the past. While there has been much discussion of the duty to recontact as a matter of theory and ethics, there has been rather little empirically based analysis of what this "duty" consists of. Drawing on interviews with 34 professionals working in, or closely with, genetics services, this paper explores what the "duty to recontact" means for healthcare professionals involved in genetics. Using a discourse analytic framework, the paper identifies three system generated discourses on recontact (governance, legal and responsibilizing discourses) and three lifeworld discourses (situating recontact as a formal duty; more loosely as an obligation; and as a personal sense of responsibility). In summary, the paper shows that the "duty" to recontact involves a complex interplay of system responsibilities with professional duties, responsibilities and obligations.
\end{abstract}

Keywords: duty to recontact; professional responsibilities; system and lifeworld; discourses of responsibility

\section{Introduction}

Developments in genetic technologies have raised the question of whether and when patients should be recontacted to give them an updated interpretation of their genetic test results at least since Pelias raised this question in 1991 (e.g. Pelias 1991). However, the combination of new genomic technologies and advances in the

*Corresponding author. Email: dohenys1@cardiff.ac.uk 
understanding of genes and disease increases pressure to clarify the nature of this "duty" and to provide professionals with advice and guidance (Pyeritz 2011).

A variety of issues may drive professionals to recontact patients. Genomic technologies produce far more data about an individual's genetic make-up than is needed to answer specific health related questions. Some of this data may "be relevant to the patient's future well-being" and thus "raises potential difficulties" (Clarke 2014, 18). Many patients who had tests in the past may be offered an improved test. In addition, interpretations of the role of particular genes in clinical diagnosis or prediction also evolve over time. The accumulation of information on genetic variants allows researchers to classify, and reclassify, variants in terms of their pathogenicity (Timmermans, Tietbohl, and Skaperdas 2017), which may prompt clinicians to reconsider past cases. Advances in knowledge of the genetic component of a disease can reveal genetic diagnoses in previously undiagnosed patients (Zhu et al. 2015). Finally, new information on how a condition can be managed, or new therapeutic interventions, might provide clinicians with reasons to want to recontact some patients.

These developments raise issues regarding the nature of the duty to recontact and the incorporation of that duty into professional practice and organizational structure. Responses to this incorporation have, thus far, been guarded. Legal and ethical analysts have problematized the nature and scope of such a duty (Hunter et al. 2001). Drawing on qualitative work with clinicians, Fitzpatrick et al. $(1999,852)$ suggest that "recontacting patients [is] an ethically desirable, but not feasible, goal." Appealing to the need for policy guidance and infrastructure to support a duty to recontact, Pyeritz (2011) recommended that "clinicians should accept with caution an explicit duty to recontact." In effect, developments in technological and research discourses that suggest a need to recontact should not translate directly into the incorporation of a duty to recontact for clinicians. In their review of the literature, Otten et al. (2015) highlighted the array of potential combinations of ethical, legal and social issues that may justify recontacting in different circumstances, and conclude that "[a] general duty to recontact in clinical genetics will therefore not be applicable" $(2015,677)$. Nevertheless, Otten el al. (2015) express support for expanding the scope of professional judgement when they argue for "focusing on the question of in which specific situations recontacting might be regarded as a good standard of care" (2015, 677). Our own contributions have used survey data to reveal the ad hoc way in which genetic services recontact patients (Carrieri et al. 2016), and the perception that practical barriers impede the goal of recontacting these patients (Carrieri et al. 2017b). We have also shown that there is some support among patients for a joint venture model of recontacting, raising the possibility that the duty to recontact may be shared between professionals and patients (Dheensa et al. 2017). Overall, while there is widespread agreement that it is right to recontact patients when relevant new information comes to light, there is little consensus on how this value should be implemented and how a duty to recontact could become part of normal care (Carrieri et al. 2017a). 
Little empirical evidence has been gathered on professional views on recontacting (Carrieri et al. 2017b; Fitzpatrick et al. 1999). This paper provides some redress for this gap using qualitative data from interviews conducted with professionals involved in medical genetics. Our aim is to explore how genetic professionals incorporate the duty to recontact into their existing practice. To achieve this, we use a nuanced discourse analytic frame drawing on both Foucault and Habermas, which we use to distinguish aspects of responsibility. Our aim is to identify the discourses with which genetic professionals make sense of the duty to recontact. In doing so, we reveal that there is no simple duty but instead a complex interplay of system responsibilities as well as professional duties, responsibilities and obligations. The paper is structured around two main sections. In the first, we develop a frame for our empirical analysis based around systemic and constructionist views of responsibility. The second section applies this frame to our empirical data to provide an analysis of how genetic professionals make sense of the "duty to recontact".

\section{Ethics, genetics and the duty to recontact}

Recontacting raises the seemingly simple question of whether to get back in touch with a patient with new information after a lapse of time. As we outlined above, this question can arise in a variety of scenarios. But over and above these, recontacting raises issues of rationing, efficiency, ethics and professionalism in genetics.

As is well documented, the scientific treatment of genetics has seen a shift from a science that focuses on deciphering genes and identifying the genetic cause of conditions, to sequencing genomes and managing complex data (Via, Gignoux, and Burchard 2010). Accompanying this transformation is a shift from a genetic reductionism and determinism focusing on single genes as direct causes of specific conditions, to a pragmatic reductionism that focuses on collecting and managing vast databases (Zwart 2007). While genomic medicine raises the possibility of providing patients with a more personalized medicine (Harvey 2009) it also raises the prospect of an increase in demand for genetic insight (Pyeritz 2011). The net result is a pressure to improve productivity by providing patients with more up to date information (Moffatt, Martin, and Timmons 2014), and a responsibilization of the professional who is expected to incorporate more complex data management processes as part of good clinical practice (Rubinstein 2008).

The recontacting discourse also links the productivity of the responsible genetic clinician with the somatic individual and the genetically at-risk patient. The development of biological citizenship has seen the formation of interest groups calling attention to the need to research their disease, with the somatic individual increasingly appropriating complex scientific discourses to manage their bodies themselves (Novas and Rose 2000). In different ways, these movements contribute to the development of personalized medicine, within which genomic sciences play a key role. Given their interest in acquiring the best available information to 
manage their own condition, the somatic individual might be interested in being recontacted should new information come to light. In addition, the "genetically at risk" patient (Bunton and Petersen 2005; Novas and Rose 2000) may be recalled to discuss their "susceptibility" to illness with a view to sustaining an acceptable level of health (Rose 2007). Recontcting also recasts patients as "unpatients" (Oduncu 2002, 55) or as "patients in waiting" (Timmermans and Buchbinder 2010, 409); no longer entirely healthy, these patients live knowing they may be recalled at any time.

The responsibilization of the genetic professional inherent in the "duty to recontact" (Rubinstein 2008) has the potential to render professionals responsible for managing their patient's data in perpetuity. Any new insight that may be relevant to a patient seen in the past, may raise the prospect of a substantive "duty" to update, inform or warn. In effect, a formalized duty to recontact may provide patients, the public and the judiciary with a lever on professional practice in medical genetics (Petrila 2001). In this sense, the further elaboration of a "duty to recontact" raises concerns about the professional conduct and professional self-governance in genetics.

\section{Conceptual framework}

Given that the aim of this paper is to explore how genetics professionals make sense of the duty to recontact, we develop a conceptual frame that situates genetic professionals as acting in relation both to systems and to lifeworlds. This reflects how genetics professionals engage with a complex scientific, professional, and bureaucratic environment and a complex lifeworld environment that both they and their patients experience. Responsibility discourses are complicated by elision and overlaps with both dimensions, and a theoretical frame is needed to tease apart these intermingled aspects.

The complementary dimensions of discourse identified by Foucault and Habermas also entail complementary aspects of responsibility. Foucault (1978) explored discourse as a system, and developed an analysis of how discourses allow ideas and practices to extend their reach by developing ideas as technologies of power. Whether as technologies of power or governmentality, discourse provides a way of responsibilizing individuals by encouraging them to inculcate the discourse and thereby incorporate the responsibilities articulated by the discourse (see Rose 1999). Exploring the assumptions actors must accept as they try to coordinate activities through communication, Habermas (1987) mapped the rational structure of understandings as they relate with our deep seated sense of responsibility. The sense that each of us has of ourselves as moral and responsible beings, comes to us through our interaction with others and Habermas (1987) reveals the rational basis of the connection between this inner worldly sense and the social and cultural world. We develop a conceptual frame that incorporates both system and lifeworld elements to reflect how clinical genetics professionals (consultants and counselors) 
manage relations between the medical branch of a scientific discipline and the personal lifeworlds of patients and their families.

\section{System generated responsibilities}

The connection between discourse and responsibility emerges in Foucault (1978) through the role of the state in shaping, legitimating and orienting how power is channeled throughout society, inculcating people and professionals to the rationale of the discourse. Following Foucault, Rose $(1999,70)$ develops the idea of responsibilization as he traces the dispersal of power away from the center of the knowing, planning, and steering state and its return to society; i.e. to businesses, organizations, localities, communities, and individuals. This process takes place as part of the formation of an intelligent and enabling state, and is based on an inculcation of the private sphere with expert rationality. Social actors are both made free and responsible for their own destiny, incorporating these actors as custodians of the destiny of society $(1999,175)$. In any event, discourses like social systems provide spaces within which the logic of rationality may unfold, revealing the responsibilities of individuals as both professionals and patients.

\section{Moral and social responsibilities in the lifeworld}

At the center of the duty to recontact is a relationship between a patient and a professional (Hunter et al. 2001; Pyeritz 2011; Rubinstein 2008). The normative force binding these two is composed of promises, hopes and expectations around diagnoses and disease management. This leads to a charged normative dimension which means where each encounter has the potential to raise topics of interest to the genetics community or to other (or not yet born) members of the patient's family. The bond is stabilized using cognitive claims; understandings of genetic/ genomic tests, interpretations and diagnoses that cover the outlooks of the professional and the patient, allowing both to think they understand each other enough to act in relation to each other. To distinguish the normative responsibilities involved in a duty to recontact, we use a framework that recognizes how cognitive constructions shape interaction enabling people to believe they understand situations in the same way, even when interpretations diverge.

Within his action theory, Habermas offers a framework that unpacks the cognitive content of normative perspectives by focusing on the rational potential inherent in the lifeworld. Habermas $(1987,126)$ situates the lifeworld as a "transcendental site" in which individuals come together and communicate. ${ }^{1}$ In this sense, the lifeworld provides a social context free from the recalcitrant structures of everyday life but whose rational potential is constitutive of these structures. The concept of communicative action allows Habermas to conceptualize how situations can be managed cooperatively through communication. For Habermas, two situations (what Habermas refers to as worlds) stand out as of primary importance in this 
situation management - communication to select the most appropriate means to achieve an end (teleological rationality), and communication aimed at identifying norms that can be accepted by all concerned (communicative reason). A third comes up as a kind of residue of the second world, and involves the internal world of an individuals' own feelings, hopes and experiences. The crucial point is that the lifeworld provides a context in which this communicative management of situations takes place $(1987,130-133)$.

Habermas's three worlds (the objective world, social world and internal or subjective world) provide the lifeworld with a rational potential that participants take for granted, while the transcendental setting of the lifeworld leaves it in principle open to construction in a potentially infinite variety of ways. These worlds provide the rational basis on which participants can believe they are coordinating action based on shared assumptions even when individual interpretations of the assumptions diverge. Different concepts of responsibility come into view depending on the aspect of the world that is being focused on. In the cultural world, duties become important, in the social world, obligations; and in the internal world personal responsibility comes to the fore. Finally, Habermas uses a sociological theory of discourse which starts with the cognitive resources provided by the different aspects of the lifeworld, and explores what happens to these resources when they are disrupted, and the role of discourse and communication in repairing and renewing them (1987, 141-144). By extrapolating from Habermas' framework and focusing on responsibility, we can provide the following framework (Table 1).

To summarize, the sense of responsibility is socially and transcendentally located in the shifting boundaries of the lifeworld. The meaning of responsibility shifts depending on the aspect of the lifeworld that is thematized, corresponding with the different worlds identified in language. Where the world of culture, reason or tradition is thematized, the form of responsibility focuses on the roles and duties held by different members. When clarity on the duties of participants is disrupted, then the meaning and rationality of duties is questioned, leading participants to reflect on their position and role in proceedings. Repairing this rationality means critiquing, clarifying and renewing the rational basis for the distribution of roles and duties.

Table 1. Responsibility and the lifeworld.

\begin{tabular}{|c|c|c|c|}
\hline $\begin{array}{l}\text { Role of communication } \\
\text { Dimension of lifeworld }\end{array}$ & $\begin{array}{l}\text { Maintaining the } \\
\text { lifeworld }\end{array}$ & $\begin{array}{l}\text { Disrupted } \\
\text { lifeworld }\end{array}$ & $\begin{array}{c}\text { Communicatively reproduced } \\
\text { lifeworld }\end{array}$ \\
\hline Cultural world & Clarifying duties & $\begin{array}{l}\text { Loss of clarity on } \\
\text { meaning }\end{array}$ & Critique and renewal of duties \\
\hline Social world & $\begin{array}{l}\text { Organising } \\
\text { obligations }\end{array}$ & $\begin{array}{l}\text { Disintegration of } \\
\text { solidarity }\end{array}$ & $\begin{array}{l}\text { Formation of consensus on } \\
\text { obligations }\end{array}$ \\
\hline Internal world & $\begin{array}{l}\text { Motivating } \\
\text { responsible } \\
\text { behaviour }\end{array}$ & $\begin{array}{l}\text { Loss of } \\
\text { motivation }\end{array}$ & $\begin{array}{l}\text { Commitment to and learning } \\
\text { about, values orienting } \\
\text { responsible behaviour }\end{array}$ \\
\hline
\end{tabular}


Where the social world of interpersonal relations is concerned, the formality of roles and duties is experienced more personally as obligations. The traditions and cultures delineating roles and duties at the cultural level shape personal relations based on interpersonal obligations obtaining between people. These obligations also take a rational structure insofar as the expectations that each will behave according to relevant norms is based on shared background assumptions and projections that serve to sustain the social order. When ruptures occur, there transpires a loss of solidarity, bringing about reflection on the norms according to which each participant can be expected to act, including those co-ordinating action and shared counterfactual norms.

Where the internal world of the participant is thematized, the sense of responsibility at issue focuses on how participants maintain the motivation to connect with their duties and obligations. A disruption of the motivation to behave responsibly weakens the motivation to accept personal responsibilities. Repairing this sense of responsibility involves reflecting on the norms, values and materials engendering commitment to responsible behavior, and on how individuals internalize this motivation through learning processes.

Bringing these back to recontacting, we can say that patients and professionals can view their situation as part of the cultural world, and to think about the reciprocal rights and duties each owe to, and can expect of, the other. Viewed as part of the social world, the duty to recontact becomes an obligation that flows from social norms which are personally held and communicatively ordered. As something that people feel internally, acting on the duty to recontact gives rise to the clinician's sense of themselves as a responsible professional.

In bringing Foucault and Habermas together to form a nuanced discourse analytic framework, we follow the work of some of the third generation of critical theorists who argue that social systems extend and expand the rationality of communicative action (see Strydom 2000).

\section{Methods}

In this paper, we explore recontacting in medical genetics using data collected as part of an ESRC funded research project. We do this using qualitative material gathered through interviews with professionals working in, or closely with, three different genetics services in England and Wales. Staff core to genetic services along with professionals who order genetic tests as part of their work, and a professional who does not order such tests but who may expect to recontact patients (a General Practitioner) were interviewed to generate an in depth understanding of professionals' experiences of recontacting, and how they understand the duty to recontact. The interviews were conducted with clinical genetics staff (clinical geneticists, genetic counselors and registrars), laboratory genetics staff, and other professionals who sometimes order genetic tests. This paper is based on interviews with 34 healthcare professionals conducted between October 
2016 and January 2018. Interviews were recorded, professionally transcribed, and shared among the research team for further analysis. The project received full ethical approval.

This paper draws together a conceptual framework with qualitative interview material to present an analysis of the discourses of responsibility used in the context of medical genetics in the UK. This combination builds on the lead author's experience (Doheny 2007) of analysing responsibility discourses in a different context. On the one hand, this conceptual framework has been adopted because its action theoretic underpinnings makes space for responsibility and is therefore sensitive to the discourses at issue here. However, this frame is only indicative of discursive aspects of responsibility, and required expansion and refinement to capture the full range of discourses observed in the data. Hence, the both the analysis and the frame were iteratively developed and refined through the analysis process.

\section{Systems discourses and the duty to recontact}

\section{Governing recontact}

As we have already noted, recontacting is enacted in an ad hoc way by different genetic services, and is seen as ethically desirable but practically difficult. As part of our interviews with professionals, we asked about policy guidance. Responses provide insight on the shape of guidance sought by professionals, and how professionals felt they would like recontact to be governed.

The interviewees preferred guidelines or aids that orient professionals on recontacting over directive policies that might standardize practice across the country. A number of interviewees described the potential usefulness of policies that shaped professional judgement. As the duty to recontact creates expectations that burden professionals with making decisions themselves, this burden leaves them with a desire for some direction:

[...] But I think, particularly consultants can feel quite vulnerable sometimes, [...] they have to make a call on these things in the absence of clear guidelines and that's a lot of responsibility. And I think there is not ... there's not really any guidance. A guideline is a guide, it's not the same as having an absolute ruling, you are allowed to interpret, you are allowed to use your clinical judgement and I think generally it's really helpful. (P13)

Always the problems I have with policies is that some people follow them too rigidly, $[\ldots]$ um but that's why I'm a consultant, as a consultant I have the ability to overrule and step aside. But as a guideline for other people who may be finding it more difficult to make a decision then I think it's good to have a policy, so they know where your fall-back position is already a default. (P5)

The question of whether or how to recontact a patient raises the need for an analysis of the new information and the situation of the patient. For these professionals, making a decision may be aided by the existence of policy guidelines, but it was 
important that these remain guides and not commands. These interviewees saw guides as aids that provide a consultant with a kind of conversation partner they can engage with as they deliberate a situation, aiding consultants in the exercise of their own judgement. As a guide, this projected conversation partner would provide all consultants with the same communication partner that they could each address individually as they made their decision:

[...] So I think a guideline may be helpful, it can be adopted or amended as fit according to the circumstances and it would probably allow a bit more standardisation across the whole country, so stop this sort of postcode lottery where some services are doing lots of recontact and others aren't. (P18)

If all professionals addressed the same guidelines, these guides would direct each in the same way, reducing inconsistency and allowing standardization.

Some interviewees described what they felt might be articulated in guides:

$[\ldots]$ it could be as simple as this you know, "if there are significant health implications for new information," so that might be surveillance it might be a new gene test, new gene available, anyway, new information because that's all we're really talking about. "If there are sufficient health implications arising from new information it is the genetics department responsibility to contact patients they know about, are at risk or would benefit from that information." I think that as a bland general statement err, that should be made and I don't think it is at the moment. (P5)

The statement that a guideline might provide to professionals could, according to $\mathrm{P} 5$, assert that there is a duty, the situation in which the duty appears, and what the duty stipulates. This is interesting because while it dispels doubt, it connects with a perception that some clinicians are unsure of how or why a duty might arise. On the one hand, the policy operates as an idealized communication partner that articulates where and how a duty arises, shaping the space in which the professional considers their options. In articulating this duty, the policy provides the genetics service with grounds to argue for the resources with which to actualize the duty since placing this duty on professionals would enable them to make a case to commissioners for improvements to data management to enable professionals to enact this responsibility:

[...] if there are guidelines say from NICE that say, "You have a duty to recontact in these scenarios," then we have the ability to go to commissioners, I guess, and say, "We need funding to put this IT system in place, because if we don't... if we don't have that ..." If we just say, "Well we think it's really important," I don't think we'd get the support. (P13)

For these interviewees, guidelines needed to remain open to the near infinite range of potential new information giving rise to the need to recontact ("The difficulty with genetics is that there are so many exceptions and so many special circumstances $[\ldots]$ the circumstances can be so variable" (P5)) that a policy guide would need to remain neutral on the circumstances giving rise to a question about recontacting. However, 
guidelines could provide some direction on the process of managing a recontact. First of all, structuring the process of informing patients that they may be recontacted by simply informing patients from the beginning of their consultation that they may be recontacted. Second, setting out how to manage the intermediate steps between the genetics department and the patient ("it's going to make it more confusing if we get in touch with the Clinician and the Clinician gets in touch with the patient, you're adding more steps in and we don't know" (P1)). Third, standardizing recontact could serve to standardize service across the country:

$[\ldots]$ because we are a discipline that deals with family and so we cover people in lots of different regions often and [...] It's bad enough when you have to say, "Well, you are getting breast screening at these intervals but your cousin is in $\mathrm{x}$ district so she'll get it more often." That's difficult enough. But saying, "Well over here we think your gene change is pathogenic and over there we are ignoring it," I mean, that I think is very damaging to patient trust. (P13)

Standardizing the situations in which a patient may be recontacted could, therefore, help standardize service provision across the country.

\section{Guidance, legal interventions, and the limits of policy}

Some interviewees expressed concern on the relationship between a recontacting policy and where and how such a duty might be defined in law. Some interviewees felt that either legal requirements already existed, or may not be unreasonable:

[...] Medical profession would always agree, there should be recall, re-contact system. I mean ... American system, you know, it works very much, you know. The clinician is sitting under ... a sword hanging over the head situation. They cannot think of delaying even for a week or so if they came to know something that would help their patient. They would [recontact]. (P3)

[...] I mean I think it wouldn't be unreasonable for like severe cases like the Huntington's disease example that we talked about, that there was a legal responsibility to get back in touch with people. (P23)

This was tempered with a concern that a legal duty may attract legal sanctions which would mean "trying people who don't comply, and giving out a punishment, and that just [feels uncomfortable]" (P27). For others, some discomfort was something of an acceptable irritant ("But I'm here to help patients not to try to protect myself from litigation" (P5)). Moreover, legal norms may be incompatible with professional duties or the administrative management of recontact:

[...] If a patient has made an active decision not to be re-contacted, then you could turn around to them and say you respect that position and you could even have a policy on that, so your policy might be you don't stick your neck out even if you think it's really, really important. Actually, you don't do that, and if your lawyers defend you on that then, legally, you're protected. (P5)

The court can't regulate something unless there's a process for it to regulate. [...] But as things stand, when it's piecemeal and you may or may not be able to find the 
information that you need and you may or may not be able to contact those other people, then I think it's a little bit unfair to make you, legally ... [laughs] (P19)

In effect, these interviewees felt that a duty to recontact could be enforced through the law in certain cases, and was more stringently defined in the US jurisdiction for medicine in general. However, the duty to recontact involves an encroachment of the law onto professional judgement, raising the prospect of professionals receiving legal sanction for having made sound professional judgements. In this sense, policies could be formulated that protected professionals from legal sanction but at the cost of the loss of their ability to exercise such judgement.

\section{Responsibilizing the patient}

A third form of systems discourse emerged with how professionals passed on some of the responsibilities of recontacting to patients. One element of recontacting involves professionals keeping abreast of developments in genomic medicine that might have an impact on the health of their patients. But this activity can be transferred from the clinician to the patient. The professionals described situations where they transferred responsibility for reviewing information, or initiating a review of a case, to the patient. Their main method was to frame the situation to encourage the patient to get back in touch with the service.

A number of interviewees recommended that their patients recontact them in three to five years:

Yeah I mean I just say ... so I'd say you know "we found this genetic variant erm it might be linked to your condition, it might not, we don't know." [...] it's just I have to say "we can't do anything else now erm we might have more information in the future. Get back in touch with us in a few years' time." And it's very much, yeah, leaving the ball in their court and I don't ... I don't know if they will come back or not really. (P9)

Clearly, this interviewee was uncomfortable with this transfer of responsibility but this appeared to be the only option. Responsibilizing the patient involved transferring both the personal and the cognitive burdens of renewing a search from the professional to the patient. Patients have their own drives and interests which animate their desire to review their case. By transferring responsibility to the patient, the professional asks the patient to consider these motivations:

... I mean, the example I have in mind is that they say, "Yes, we'll contact in a few years' time." I mean, who knows whether they will do, [...] But they did seem interested maybe because of the other family members more than themselves, because if they are affected they know that they are going to see a specialist, but what about siblings or parents? So they are, yes, I think they are willing to. (P16)

I will quite often say "if you are still interested you know, if you phone me in three or five years to see if there's anything new going on." (P25) 


\section{S. Doheny et al.}

The transfer of responsibility takes place in the context of rapidly moving testing technologies, where there is uncertainty about when an appropriate test might become available:

For example, for cardiomyopathy, [...] so if I've withheld a gene test or I know that gene testing is advancing so quickly that there may be new things round the corner and it's negative on this occasion, I would ask them to contact me again. If there was a change in the family circumstances, any way, around five years often, or three to five years depending on the condition. [...] (P18)

On the other hand, by responsibilizing the patient, the professional sometimes transfers a responsibility to an individual who has little appreciation of the potential gravity of this task:

... so I think people are often quite trusting of medical staff and think that if they had a risk of breast cancer or something somebody would tell them. And what I find difficult is that sometimes we put that burden of responsibility on the patient and I, a, don't think the patient entirely realises that that's what we're doing and I don't think that's really what Doctors do. Like we usually have ownership over our patients and look after them, do you know what I mean ... so if there's something that could be dan, er, you know a danger to them I think people do assume that somebody will come and tell them. (P33)

Equally, the patient may find this responsibility a great burden. Thus, the following laboratory geneticist described a worry that patients would look for information on variants for which there is very little data:

[...] what I worry about slightly is people then assuming a diagnosis or doing too much Googling et cetera, especially where it's a research variant, and in theory we haven't tested on the NHS [where testing has been funded through a research project]. And I'm always quite keen to state this is a research finding, it has to be tested through a proper accredited lab and by definition at that stage we haven't done that, $[\ldots]$ (P30)

Transferring responsibility for recontacting to the patient, therefore, involved some discomfort for clinicians as they could not be sure how the patient would manage this responsibility. Patients could get back to the genetics service if they were interested in having an update, or forget about the test. There remained a concern that patients would either not appreciate the gravity of the potential information, would not interpret changes in family circumstances as potentially relevant information, or would obsess over the information.

\section{Lifeworld discourses and the duty to recontact}

\section{Recontact and duty discourses}

The duty discourse focuses on an agreement forged between the clinician and the patient. This discourse draws on assumptions situating both participants as rational adults, who come together and form a contract. Thus, participants are free in the 
liberal sense, that is, they have reflected on their own interests, and have decided to follow what they see as the best course of action. The patient contracts the professional to identify the molecular cause of an illness, and then to keep abreast of developments pertinent to the condition. The professional accepts this commission, and provides a service aimed at identifying a diagnosis and contributing toward the management of the condition. In effect, once the participants have forged a contract, the patient has a right to expect a service, and the professional has a duty to provide this service. Only two interviewees drew principally on this discourse:

Well, I think you are in a form of contract with patients, so patients come to see you and establish a contract and which you are going to perform certain parts of that contract and that contract is to investigate them and to notify them of that investigation. Now, if they specifically indicate that they don't want you to fulfil part of that contract, then you are obliged to respect those wishes unless there is major risk involved and then you have to re-evaluate that, and I think that that contract does not terminate when you have finished the consultation and say "we haven't found anything." I think your contract is still live and that the patient has still made that request. (P15)

Within this discourse, the bond between the clinician and the patient was focused on the effort to secure a genetic diagnosis. By agreeing to seek out a genetic diagnosis for a patient, the clinician assimilated a duty and the patient acquired a right to expect the clinician to fulfill this duty. Interestingly, this duty discourse has no time limit. It focuses on the activity of "investigating" the patient's genetic information to reveal a genetic diagnosis which may involve somehow keeping abreast of developments relevant to the case (either in terms of diagnosis, management or treatment). Because the clinical geneticist performs her duty by searching for a diagnosis, this clinician can only be understood as fulfilling her duty when a satisfactory genetic diagnosis is achieved.

The trouble with this view is that it loads the professional with a more formal expectation than may reasonably be expected. The reality is that the clinician is also an individual with their own personal and career history, working within a clinical system whose commissioning arrangements have not supported the service reconsidering past cases, using somewhat dated data management systems. However, the trouble for clinicians was that the doctor patient relationship within such a specialized area increased their sense of duty:

Erm, I think we're genetic Doctors ... and we've got a responsibility to our patients [...] I know that's not easy, but I, we probably advocate that we should all have a sort of ongoing list of our patients and every so often review that and check on what, just because I think that's you know. [...] if we bring it [the patient file] out and do a quick literature search and say right something has changed then we do need to bring them back and I think if it's information about a genetic result ... who else's responsibility is it other than ours? So that's sort of the whole purpose of the speciality I would say. (P33) 


\section{S. Doheny et al.}

Thus, whereas P15 begins with a formalized duty, P33 arrives at an inescapable conclusion that the expectation of the speciality is that they recontact when appropriate.

Because this duty rests on the bond created by the activity of identifying and managing a genetic diagnosis, then the duty discourse appears whenever relevant new information is found. While many interviewees drew more on the "obligation" discourse detailed below, they also drew on the "duty" discourse where new information relevant for a patient came to light. For example, the sudden appearance of new information relevant to identified case(s) brings the duty discourse into view:

Yeah, yeah, I usually leave it to them, because, and I have not actively made an effort over the past year looking at all of the VUS, looking at literature to see whether there's any new paper published. I haven't done that [...] but I think you know erm if there were something which came up in the interim, which is quite obvious right in front of me and it comes, and even though I have not put in the letter that I will contact you if there's any new information, I would write to them, to say "I've met you before, you know this is something that has recently come to my attention about this particular gene, do you want to come and discuss." (P6)

Clearly, the appearance of information pertinent to a patient's condition before a professional brings a legitimate expectation that the professional recontact the patient. That is, a duty for the professional to recontact a patient accompanies the appearance of relevant information.

\section{Recontact and obligation discourses}

The second view holds that there is a duty to the patient, but this is a duty held by the relevant clinician. In this discourse, the expectation is that the clinician bears the patient in mind when they come upon information that might be relevant to the patient's condition. This is a weaker expectation than found in the duty discourse, and limits expectations to those that can reasonably be made of individual professionals:

Yeah, well exactly, I think you'd feel more responsible if you saw, oh "I saw someone last year" and that seems quite recently, I should do that. And then you think you know "I only saw you last year and you didn't tell me about this," whereas if you'd seen them ten years before they probably wouldn't expect you to remember them. And probably wouldn't. I mean certain cases where you've had a lot to do with, they might expect and you might expect more, but the average patient is probably, time is probably a bit relevant. So I don't think, not legally, but logistically. (P25)

This discourse still draws on a conception of duty. The clinician has accepted a mandate to keep abreast of information relevant to the condition. But here, the bond is not a formal one in which the clinician continues to be bound by the original duty to that particular patient. The bond is conditional on the capacities and capabilities of the clinician to manage information, bear details of particular patients in mind, and correlate information with individual cases. This weakens the normative 
force of the bond between the professional and patient. Rather than binding these two using the expectation that a formal duty remains relevant in the same way as it was initiated, the bond transmutes to something more like an obligation in which the reasonable expectations that can be made of the people involved become relevant. In a sense, the obligation discourse highlights the work and commitment underscoring the duty discourse.

The obligation discourse was principally drawn upon to emphasize the changing position of the clinician in the clinician-patient relationship. Not only was the passing of time causing memory of the patient to fade, but information about the presentation of genetic conditions can change complicating the process of reviewing past records in light of current knowledge:

Clinician: But it [a database] still won't do what I want, which is, "Please give me a list of patients with left big toe syndrome." And don't forget, when you get a brand new, say, "mutation" as it says there, it may be a very muddy sort of phenotype. You know, like boys with mental retardation ... who've got small ears and big testicles ... have this gene. Now, how am I going to pull back boys with mental retardation, small heads and big testicles? There is never going to be a database with that on it, is there? Interviewer: No. No.

Clinician: You know, all I can do is think about all the patients I've seen and try and think, now, did anybody fit that pattern? (P7)

The problems here range from the terms used to describe and record features and the extent to which these correspond with the terms used in current discussions, through to situations where features that were not seen as relevant and in need of recording in the past, turn out to be relevant in contemporary reviews. Thus, individual selection of cases, the data recorded on cases and the terms used to record data can all shape the situation in which a decision about recontacting a case may be made. So, it is not just the capriciousness of human capacities that attenuates duty to obligation, but also professional norms and practices.

\section{Recontact and the responsibility discourse}

The sense of duty also involves the exercise of a moral sensibility. Whereas duty arises from expectations that bind self and other, the personal sense of responsibility arises as a pre-theoretic, pre-ontological commitment to do the right thing for a person who calls for help. Moreover, while duty involves some readily identifiable action, no such luxury is afforded the responsible person. Bauman (1993) talks of the importance of the moral caress to underline the uncertainty and fragility of the willingness "to be for the other."

Paying attention to the needs of the other without quite knowing what to do presents challenges for clinicians. Such challenges became particularly evident where the clinician seeks to balance the patient's right not to know their genetic status against the potential value of this information for the patient or their family: 
They could put it [a letter], bin it and it may be that. You'll have discussed with the consultant or your colleague and you say "actually I'll drop them one more letter and say 'if we don't hear from you we'll understand we don't want to get in touch"' and perhaps copy that to the GP. Because at least then there's someone else there that knows. You know. Erm, it may be that for sudden cardiac death or something, or for something where there can be a surveillance that you write a stronger letter. (P34) No, if a patient has clearly stated, is informed and has clearly stated they don't want to be contacted about something, it's like when our patients decline treatment, if they're informed and they've made that decision that ... they've declined it then they've declined it, that's their right. (P1)

[...] because I think sometimes what people decide at one time changes. But the difficulty is you don't know that, and it may be just that they were really struggling at that that time. [...] It would be helpful if the notes are a bit more extensive and say why they don't want to be re-contacted. [...] (P24)

The professionals found that initiating a communication with a patient who may not want to receive this communication unsettling. Not hearing back from patients left the P34 with a feeling that perhaps they had not been clear enough about the gravity of the situation, but trying to balance this with a respect for the patient's right not to know. P1 was more willing to respect a patient's right not to know, and P24 feels patients may ask not to be recontacted at a time when they are overwhelmed by the situation, and this feeling and their decision may change. So where the "duty" to recontact applies, the professional finds themselves trying to interpret the meaning of their responsibility to respect the autonomy of the patient.

Once the clinician has decided that there is a duty to recontact a patient, they need to decide how best to exercise this duty. This means paying attention to the patient as a person. Carrying out this duty involved gathering insight on the patient to enable the clinician to judge the meaning of responsible conduct in this situation:

It depends. I'll go through the notes and my letters first, to see how I've contacted them in the past, because usually there's some record of how they'd like to be contacted. If I've already done testing there'll be some record of how they wanted to be contacted with that result. So that will give me a clue. [...] And usually it would be by letter or phone. (P24)

Yes. So if I know them myself, and it had been fairly recently like within the last five years, easily be in my memory, I would probably write to them myself. But if I have had no contact or it's been many years or they were a family that were seen by my registrar many years ago and I never saw them, I would try and go through their physician, be it their hospital practitioner or their GP [...] (P18)

The modality of the recontact was based on an appreciation of the patient, and their potential receptivity to the new information. Interviewees described various ways in which they carried out their duty to recontact in a responsible manner. One interviewee described using memory jogs in notes to help her remember patients so that she could adjust her recontact. Another described using letters as a way of ensuring 
patients have time to think so that "they may have prepared themselves, even only if it's a little bit psychologically, to find out" (P8).

\section{Conclusions}

This article applied a critical theoretic frame to qualitative data gathered through interviews with people working in or around genetic services, to explore the complexity of the duty to recontact. Specifically, we show that recontacting in medical genetics involves layers of ideas and concepts. First, there is a clear desire for policy guidance on the part of the professionals as a way of standardizing processes, and orienting professional practice. This involves a willingness to accept some governance on recontacting, and to act in accordance with the steer that might be provided by guidance even if this might mean risking legal sanction. Through the concept of responsibilization, we show that recontacting reaches through to the experiences of patients who are already being asked to manage the recontact process.

Recontacting is not just a systems matter, but also encompasses the lifeworld experiences of the professionals, patients and their families. In this dimension, some professionals draw on a duty discourse to understand their connection with the patient as a form of contract. Using this duty discourse, the professional accepts a duty to keep abreast of developments pertinent to a patient's condition, enabling the patient to expect this of the professional. This rationale seems sensible when the complexity of genetics and genomic research is taken into account, and the expertise needed to comprehend whether or how developments may be relevant. Next, a discourse emerges which recognizes that professionals have a duty to patients, but pragmatizes this duty in light of the limitations of the professional involved. This discourse situates the professional as a human, with all the frailties and limitations of any other human, and weakens the duty to recontact to the social obligations we each can expect of each other. On this discourse, the professional is obliged to keep the patient in mind when they come upon new developments, but only to the extent that they can reasonably be expected to recall the details of any particular case. A professional might simply forget, retire, or move, thus undermining any formal or contractual duty to recontact. This recognition of the limits of professional capabilities erodes the commitments that underpin a duty discourse allowing a discourse of obligation to emerge. This discourse also recognizes the difficulties genetic services face in incorporating the duty to recontact, and how the exercise of this duty rests on the shoulders of individual professionals. Finally, recontacting raises complex issues for professionals, stimulating a discourse on their responsibilities to their patients. Trying to do their best for individual patients, who may not wish to think about a traumatic experience they had in the past, or who have indicated they would prefer not to hear from the genetics service, professionals drew on a discourse of personal responsibility. The professionals interviewed varied in 
their willingness to engage in this discourse. Some preferred to recontact in every relevant case; some felt their duty to recontact could override the patient's right not to know; others thought through each case individually. Thus, not only was there a policy discourse taking place at a systems level, but interviewees drew on sets of ideas that can be distinguished in terms of their duties in a cultural world, their obligations as members of a social world, and their responsibilities as individual professionals striving to do their best for their patients.

Recontacting, therefore, is not a singular "duty," but a complex interplay of shifting discourses of responsibilities. Given this complexity, stabilizing a duty to recontact requires a policy environment that helps both professionals and patients understand what is expected of them while fostering the commitment of professionals to their patients. The development of a prescriptive policy determining recontact may connect easily with a formal sense of professional duty, but also shoulders professionals with specific and potentially onerous duties. However, the complex nature of genetics means that such a policy might be of little use in practice. Adopting a guidance framework that is less prescriptive may recognize how recontact is conducted by individual professionals, and is subject to their idiosyncratic and human shortcomings. Either framework will shape how professionals feel toward their patients, molding the sense of responsibility in ways that might foster or undermine the commitment of professionals.

\section{Funding}

The research on which this paper is based was funded by the Economic and Social Research Council (ESRC) $(\mathrm{ES} / \mathrm{L} 002868 / 1)$.

\section{Note}

1. Habermas's (1987) concept of the lifeworld has been taken up and applied in medicine most notably by Mishler (1984). However, for us, Mishler's use of this framework remains too close to Habermas (1987), in particular, to the way Habermas developed interaction between the lifeworld and the system into a theory of society. In effect, Mishler accepted Habermas' 'boxer model' of society (Baxter 1987). This theoretic framework tends to reify both system and lifeworld, but situating the lifeworld in opposition to the system (or medicine) can lead analysts to ignore how clinicians have their own lifeworld experiences which they bring to the clinical encounter (see Barry et al. 2001). In this paper, we take up Habermas' idea of the lifeworld as a product of the communicative potential of language, and use this conception in line with the work of later critical theorists who view social systems as the radical extension of this communicative potential (Eder 2007).

\section{ORCID}

Shane Doheny @ 1 http://orcid.org/0000-0003-0529-7301

Angus Clarke (ㅇ) http://orcid.org/0000-0002-1200-9286

Daniele Carrieri (1) http://orcid.org/0000-0002-3143-8430

Naomi Hawkins ๑ http://orcid.org/0000-0002-8290-7233 
Anneke Lucassen (1) http://orcid.org/0000-0003-3324-4338

Susan Kelly (1) http://orcid.org/0000-0003-1045-4615

\section{References}

Barry, C. A., F. A. Stevenson, N. Britten, N. Barber, and C. P. Bradley. 2001. "Giving Voice to the Lifeworld. More Humane, More Effective Medical Care? A Qualitative Study of DoctorPatient Communication in General Practice." Social Science and Medicine 53 (4): 487-505.

Bauman, Z. 1993. Postmodern Ethics. Oxford: Blackwell.

Baxter, H. 1987. "System and Life-World in Habermas's 'Theory of Communicative Action'.” Theory and Society 16 (1): 39-86.

Bunton, R., and A. Petersen. 2005. Genetic Governance: Health, Risk and Ethics in a Biotech Era. London: Routledge.

Carrieri, D., S. Dheensa, S. Doheny, A. J. Clarke, P. D. Turnpenny, A. M. Lucassen, and S. E. Kelly. 2017a. "Recontacting in Clinical Genetics and Genomic Medicine? We Need to Talk About It." European Journal of Human Genetics 25 (5): 520-521.

Carrieri, D., S. Dheensa, S. Doheny, A. J. Clarke, P. D. Turnpenny, A. M. Lucassen, and S. E. Kelly. 2017b. "Recontacting in Clinical Practice: An Investigation of the Views of Healthcare Professionals and Clinical Scientists in the United Kingdom." European Journal of Human Genetics 25 (3): $275-279$.

Carrieri, D., A. M. Lucassen, A. J. Clarke, S. Dheensa, S. Doheny, P. D. Turnpenny, and S. E. Kelly. 2016. "Recontact in Clinical Practice: A Survey of Clinical Genetics Services in the United Kingdom." Genetics in Medicine 18 (9): 876-881.

Clarke, A. J. 2014. "Managing the Ethical Challenges of Next-Generation Sequencing in Genomic Medicine." British Medical Bulletin 111 (1): 17-30.

Dheensa, S., D. Carrieri, S. Kelly, A. Clarke, S. Doheny, P. Turnpenny, and A. Lucassen. 2017. "A 'Joint Venture' Model of Recontacting in Clinical Genomics: Challenges for Responsible Implementation." European Journal of Medical Genetics 60 (7): 403-409.

Doheny, S. 2007. "Responsibility and the Deliberative Citizen: Theorizing the Acceptance of Individual and Citizenship Responsibilities.” Citizenship Studies 11 (4): 405-420.

Eder, K. 2007. "Cognitive Sociology and the Theory of Communicative Action: The Role of Communication and Language in the Making of the Social Bond." European Journal of Social Theory 10 (3): 389-408.

Fitzpatrick, J. L., C. Hahn, T. Costa, and M. J. Huggins. 1999. "The Duty to Recontact: Attitudes of Genetics Service Providers." American Journal of Human Genetics 64 (3): 852-860.

Foucault, M. 1978/1981. The History of Sexuality. Harmondsworth: Penguin.

Habermas, J. 1987. The Theory of Communicative Action Vol.2, Lifeworld and System: A Critique of Functionalist Reason. Cambridge: Polity.

Harvey, A. 2009. "From Genetic Risk to Post-genomic Uncertainties: Nutrigenomics and the Birth of the 'Genetic Entrepreneur'." New Genetics and Society 28 (2): 119-137.

Hunter, A. G. W., N. Sharpe, M. Mullen, and W. S. Meschino. 2001. "Ethical, Legal, and Practical Concerns about Recontacting Patients to Inform Them of New Information: The Case in Medical Genetics." American Journal of Medical Genetics 103 (4): 265-276.

Mishler, E. G. 1984. The Discourse of Medicine: Dialectics of Medical Interviews. Norwood, NJ: Ablex.

Moffatt, F., P. Martin, and S. Timmons. 2014. "Constructing Notions of Healthcare Productivity: The Call for a New Professionalism?” Sociolology of Health and Illness 36 (5): 686-702.

Novas, C., and N. Rose. 2000. "Genetic Risk and the Birth of the Somatic Individual." Economy and Society 29 (4): 485-513. 
Oduncu, F. S. 2002. "The Role of Non-directiveness in Genetic Counseling." Medicine, Health Care, and Philosophy 5 (1): 53-63.

Otten, E., M. Plantinga, E. Birnie, M. A. Verkerk, A. M. Lucassen, A. V. Ranchor, and I. M. Van Langen. 2015. "Is There a Duty to Recontact in Light of New Genetic Technologies? A Systematic Review of the Literature." Genetics in Medicine 17 (8): 668-678.

Pelias, M. Z. 1991. "Duty to Disclose in Medical Genetics - A Legal Perspective." American Journal of Medical Genetics 39 (3): 347-354.

Petrila, J. 2001. "Genetic Risk: The New Frontier for the Duty to Warn." Behavioral Sciences and the Law 19 (3): 405-421.

Pyeritz, R. E. 2011. “The Coming Explosion in Genetic Testing - Is There a Duty to Recontact?" New England Journal of Medicine 365 (15): 1367-1369.

Rose, N. 1999. Powers of Freedom: Reframing Political Thought. Cambridge: Cambridge University Press.

Rose, N. 2007. The Politics of Life Itself: Biomedicine, Power and Subjectivity in the Twenty-First Century. Oxford: Princeton University Press.

Rubinstein, W. S. 2008. "Roles and Responsibilities of a Medical Geneticist." Familial Cancer 7 (1): 5-14.

Strydom, P. 2000. Discourse and Knowledge: The Making of Enlightenment Sociology. Liverpool: Liverpool University Press.

Timmermans, S., and M. Buchbinder. 2010. "Patients-in-Waiting: Living Between Sickness and Health in the Genomics Era." Journal of Health and Social Behavior 51 (4): 408-423.

Timmermans, S., C. Tietbohl, and E. Skaperdas. 2017. "Narrating Uncertainty: Variants of Uncertain Significance (VUS) in Clinical Exome Sequencing." BioSocieties 12 (3): 439-458.

Via, M., C. Gignoux, and E. G. Burchard. 2010. "The 1000 Genomes Project: New Opportunities for Research and Social Challenges." Genome Medicine 2 (1): 3.

Zhu, X., S. Petrovski, P. Xie, E. K. Ruzzo, Y.-F. Lu, K. M. McSweeney, B. Ben-Zeev, et al. 2015. "Whole-Exome Sequencing in Undiagnosed Genetic Diseases: Interpreting 119 Trios." Genet Med 17 (10): 774-781.

Zwart, N. H. 2007. "Genomics and Self-Knowledge: Implications for Societal Research and Debate." New Genetics and Society 26 (2): 181-202. 